\title{
FORMAÇÃO DE PROFESSORES DE CLASSE HOSPITALAR EM SAÚDE MENTAL COMO RESULTANTE DE UMA PESQUISA-AÇÃO EXISTENCIAL
}

\author{
FORMACIÓN DE PROFESORES DE ESCUELA HOSPITALARIA EN SALUD \\ MENTAL COMO RESULTANTE DE UNA INVESTIGACIÓN-ACCIÓN \\ EXISTENCIAL
}

TRAINING OF HOSPITAL CLASS OF TEACHERS IN MENTAL HEALTH AS A RESULT OF EXISTENTIAL ACTION RESEARCH

\author{
Ricardo Antonio Gonçalves TEIXEIRA ${ }^{1}$ \\ Rodrigo Carvalho do Rego BARROS ${ }^{2}$ \\ Uyara Soares Cavalcanti TEIXEIRA ${ }^{3}$ \\ Mário José de SOUZA ${ }^{4}$ \\ Nelson Filice de BARROS 5
}

RESUMO: Este estudo elege como objetivo investigar a saúde do professor atuante em classe hospitalar na rede pública estadual de educação em Goiás. Enquanto metodologia utiliza-se a pesquisa-ação na perspectiva existencial. Como resultante da investigação de campo, foi proposto, em parceria com os atores e autores da pesquisa, um curso de formação em saúde mental com os docentes do Núcleo de Atendimento Educacional Hospitalar, valendo-se do método Problem-Based Learning (PBL), uma estratégia pedagógica de aprendizagem baseada em problemas e que elege como foco o aprendizado centrado no aluno. A participação efetiva, colaborativa e engajada de autores e atores na pesquisa trouxe, como resultado, aprofundamentos teóricos e metodológicos sobre o tema proposto, reflexão sobre as dificuldades no atendimento de casos envolvendo transtorno mental, maior conhecimento sobre doenças mentais e seus reflexos no comportamento, esclarecimentos sobre procedimentos de ação e construção de protocolos de encaminhamentos.

PALAVRAS-CHAVE: Classe hospitalar. Formação de professor. Saúde mental. Pesquisa-ação.

RESUMEN: Este estudio elige como objetivo investigar la salud del profesor actuante en escuela hospitalaria en la unidade pública estatal de educación en Goiás. Como resultado de la investigación de campo, se propuso, en asociación con los sujetos del

\footnotetext{
${ }^{1}$ Universidade Federal de Goiás (UFG), Goiás - Brasil. Programa de Pós-Graduação em Educação (PPGE) e em Saúde Coletiva (PPGSC). E-mail: professorricardoteixeira@gmail.com.

${ }^{2}$ Universidade Federal de Goiás (UFG), Goiás - Brasil. Programa de Pós-Graduação em Saúde Coletiva (PPGSC. E-mail: rodrigokarvalho@yahoo.com.br.

${ }^{3}$ Universidade Federal de Goiás (UFG), Goiás - Brasil. Mestrado Profissional em Matemática em Rede Nacional (ProfMAT). E-mail: uyaras@gmail.com.

${ }^{4}$ Universidade Federal de Goiás (UFG), Goiás - Brasil. Mestrado Profissional em Matemática em Rede Nacional (ProfMAT). E-mail: mariojsouza@gmail.com.

${ }^{5}$ Universidade Estadual de Campinas (UNICAMP), Campinas - SP - Brasil. Programa de Pós-Graduação em Saúde Coletiva (PPGSC).
}

Temas em Educ. e Saúde, Araraquara, v.13, n.2, p. 317-334, jul./dez. $2017 . \quad$ E-ISSN: 2526-3471 
estudio y autores de la investigación, un curso de formación en salud mental con los profesores del Núcleo de Atención Educativa Hospitalaria, utilizando el método Problem-based Learning (PBL), una estrategia pedagógica de aprendizaje basada en problemas y que tiene como principio el aprendizaje centrado en el alumno. La participación efectiva, colaborativa y comprometida de los sujetos en estudio y autores en la investigación trajo, como resultado, profundizaciones teóricas y metodológicas sobre el tema propuesto, reflexión sobre las dificultades en la atención de casos involucrando trastorno mental, mayor conocimiento sobre enfermedades mentales y sus reflejos en el estudio comportamiento, aclaraciones sobre procedimientos de acción y construcción de protocolos de encaminamientos.

PALABLAS CLAVE: Clase hospitalaria. Formación de profesor. Salud mental. Investigación-acción.

ABSTRACT: This study aims to investigate the health of the hospital class teacher in the state department of education in Goias. The methodology used was existential research-action. As a result of the field research, a training course in mental health was proposed in partnership with the actors and authors of the research with the teachers of the Nucleus of Hospital Educational Attendance, using the Problem-Based Learning $(P B L)$ method, a pedagogical strategy of problem-based learning that focuses on student-centered learning. The effective, collaborative and engaged participation of authors and actors in the research brought, as a result, theoretical and methodological insights on the proposed theme. Reflection on the difficulties in attending cases involving mental disorder, greater knowledge about mental illness and its reflexes on behavior, clarification on action procedures and construction of referral protocols.

KEYWORDS: Hospital Class. Teacher training. Mental health. Research-action.

\section{Caminhos da investigação}

Este texto é resultado de parte de uma pesquisa realizada com professores de classe hospitalar ligados ao Núcleo de Atendimento Educacional Hospitalar do Estado de Goiás (NAEH), órgão vinculado à Gerência de Ensino Especial (GEEE), da Secretaria de Estado de Educação, Cultura e Esporte (SEDUCE). Enquanto objetivo, a pesquisa se propôs investigar a saúde desse profissional da educação na lida com educandos em tratamento de saúde.

A pesquisa se apresenta como estudo qualitativo sobre a saúde mental com professores de classe hospitalar e atendimento educacional domiciliar. A abordagem utilizada no estudo foi a da pesquisa-ação existencial, proposta por Barbier (2002).

A classe hospitalar é uma modalidade de atendimento pedagógico contemplada, dentre outros, pela Resolução n. 2, de 11 de setembro de 2001 (BRASIL, 2001), estruturada e organizada para o atendimento educacional hospitalar e domiciliar em 
todos os estado brasileiros pelo instrumento do Ministério da Educação (MEC) intitulado "Classe Hospitalar e Atendimento Pedagógico Domiciliar: estratégias e orientações" (Brasil, 2002).

Se constituíram como sujeitos do estudo os profissionais da educação da SEDUCE lotados no NAEH. Participaram da pesquisa a coordenadora geral do NAEH, o psicólogo institucional deste órgão, bem como as professoras que realizam atendimento educacional hospitalar ou domiciliar. Participaram, ao todo na pesquisa, 150 profissionais da educação. O estudo foi realizado no período de março de 2015 a maio de 2016.

No caso das professoras de classe hospitalar e atendimento educacional domiciliar, em função de lidarem com alunos doentes ou em estado de convalescença, o sofrimento em estudo ocorre no contato com as angústias dos alunos em situação de sofrimento frente ao processo de tratamento. Lidar com limitações físicas e psicossociais, muito em função da mudança da rotina social, geram angústias aos alunos e essas angústias afetam o professor, devido ao vínculo e à empatia criada para a efetivação do trabalho pedagógico junto ao aluno.

A definição de pesquisa-ação utilizada por Thiollent (1988) mostra o engajamento que a pesquisa-ação tem com as transformações, visando à resolução de problemáticas dentro de grupos. Essa característica faz dessa metodologia uma proposta adequada para aplicação em ambientes de trabalho que necessitem de uma transformação de uma realidade específica.

[...] a pesquisa-ação é um tipo de pesquisa social com base empírica que é concebida e realizada em estreita associação com uma ação ou com a resolução de um problema coletivo e no qual os pesquisadores e os participantes representativos da situação ou do problema estão envolvidos de modo cooperativo ou participativo (THIOLLENT, 1988, p. 14).

Para Barbier (2002) “A pesquisa-ação torna-se a ciência da práxis exercida pelos técnicos no âmago do seu local de investimento" (p. 59). A pesquisa buscou aproximações plenas e constantes entre os sujeitos da investigação com o tema em discussão e pesquisadores no sentido de uma compreensão mais ampla e profunda. A participação integral dos sujeitos da pesquisa com os pesquisadores na produção de conhecimentos é uma característica da pesquisa-ação que não ocorre na pesquisa convencional. Enquanto que a pesquisa convencional busca um distanciamento do objeto abordado, uma neutralidade, na pesquisa-ação, de forma oposta, busca a 
implicação do pesquisador e dos participantes na pesquisa, pressupondo uma ação efetiva dos interessados.

Essa implicação do pesquisador e dos participantes na pesquisa e na problemática abordada é o que, segundo Barbier (2002), permite estudar dinamicamente os problemas, decisões, ações, negociações, conflitos e tomadas de consciência que ocorrem entre as pessoas no campo de pesquisa, durante os processos de transformação. $\mathrm{Na}$ pesquisa convencional, no entanto, perde-se esse conhecimento dinâmico das relações, pois o distanciamento e a neutralidade propostos vão investigar somente os aspectos individuais e superficiais como opiniões, atitudes, motivações e comportamentos (THIOLLENT, 1988, p. 19).

O estudo em apresentação buscou investigar um fenômeno na sua dinâmica de transformação, reconhecendo e destacando a importância dessa perspectiva, até então considerada irrelevante pela pesquisa convencional devido à dificuldade de controle e, portanto, de verificação e validação da pesquisa.

O objeto de estudo da pesquisa-ação existencial, proposto enquanto modelo de estudo, é, portanto, um objeto subjetivo e o que se busca é a transformação da uma realidade interna ao sujeito ou sujeitos. Mesmo que, por vezes, possam ocorrer, durante a pesquisa, mudanças e ações sobre a realidade externa, essa sempre visa a alcançar a realidade interna dos sujeitos.

A pesquisa-ação existencial "expressar-se-á antes como uma arte de rigor clínico, desenvolvida coletivamente, com o objetivo de uma adaptação relativa de si ao mundo" (BARBIER, 2002, p. 67). Assim sendo, a pesquisa-ação existencial se aproxima da clínica psicológica que propõe a transformação psíquica do sujeito, trabalhando as problemáticas subjetivas e, para tanto, a arte de rigor clínico é muito mais adequada como referência para atuação no campo de pesquisa do que o rigor metodológico da ciência clássica.

O método de pesquisa-ação é dividido em quatro temáticas: as técnicas em pesquisa-ação; a identificação do problema e a contratualização; o planejamento e a realização em espiral; a teorização, a avaliação e a publicação dos resultados (BARBIER, 2002). Estas temáticas se constituem no roteiro geral de qualquer pesquisaação. 


\section{Pesquisa-ação predominantemente existencial}

O primeiro quesito para realizar uma observação participante predominantemente existencial é ser aceito pelo grupo ou pela comunidade pesquisada. No caso desta pesquisa, a aceitação ocorreu de forma gradual. A realização de trabalhos anteriores facilitou a entrada de novos membros no grupo.

A noção de campo de pesquisa não tem sua delimitação rigidamente estipulada. Todos os lugares ou situações, desde os oficiais e formais (reuniões, conselhos de administração, assembleias e etc.) até os informais (cafés, lugares recreativos, de culto, reuniões familiares, encontros de confraternização) se constituíram como fontes de dados para pesquisa. Para Barbier (2002), é preciso estar atento não só aos acontecimentos em lugares formais, mas também nos informais. Muitas vezes, um acontecimento imprevisto, geralmente dramático, como um acidente, incidente etc. pode ser proveitoso para a pesquisa, a isso o autor em tela chama de "lugar do acontecimento" e, segundo ele, nesses momentos o imaginário e os estereótipos enraizados no grupo afloram, com todo seu vigor.

Os documentos oficiais, também, se fizeram importantes nos processos de investigação, pois os arquivos da instituição que se pesquisa podem conter muitas informações que ajudem a esclarecer a vida imaginária e afetiva do grupo.

Buscamos, enquanto pesquisadores, captar as questões existenciais do grupo pesquisado, como angústias e sofrimentos que afligem seus imaginários, assim como as transformações que ocorrem nesse imaginário. Nesse objetivo, Barbier (2002) propõe como técnica a utilização da escuta sensível que segundo ele apoia na empatia. Segundo propõe,

O pesquisador deve saber sentir o universo afetivo, imaginário e cognitivo do outro para "compreender do interior" as atitudes e os comportamentos, os sistemas de ideias, de valores, de símbolos e de mitos (p. 94).

É sobre a escuta sensível que recai toda a peculiaridade que distingue a pesquisaação predominantemente existencial dos outros tipos de pesquisa-ação. O olhar sobre o objeto, que a escuta sensível requer, é o que permite um conhecimento que se aproxima do que há de essencial na dinâmica dos indivíduos e do grupo pesquisado; é o que apreende a relação conflituosa com o objeto estudado, no caso a angústia existencial, ou sofrimento. 
A escuta sensível não é uma rotulação social, o que fixaria os sujeitos em seus rótulos, negando-lhes uma abertura para outros modos de existência, que evitam o conformismo social inconsciente, que afeta negativamente os sujeitos. A escuta sensível não é a projeção de nossas angústias ou de nossos desejos, exigindo do pesquisador um trabalho de autoconhecimento, para evitar que seus conteúdos interfiram na pesquisa. Um dos perigos, apontados por Thiollent (1988), de não se realizar uma autorreflexão é o risco de ativismo, quando o desejo do pesquisador se sobrepõe aos interesses do grupo considerado.

A escuta sensível e multirreferencial também não está assentada sobre a interpretação dos fatos. O cuidado está em não impor um sentido e, sim, em atribuir um sentido, posto que "Para uma pessoa, tudo é continuamente retraduzido em função do contexto. Essa retradução somente a pessoa em questão pode, em última instância, decodificá-la" (BARBIER, 2002, p. 98). A atribuição do sentido não deve vir somente do pesquisador, numa relação de imposição da sua ideia perante o grupo, mas de uma construção em conjunto na qual o grupo tenha uma participação ativa.

A dialética negativa foi utilizada para explicar a escuta sensível multirreferencial, para que o pesquisador não fique preso a uma forma de ação estereotipada e rígida, que não se adapte às diferentes demandas do campo de pesquisa. Sabendo do que não é, ou seja, dos erros que não deve cometer, o pesquisador deve usar de sua sensibilidade para observar e agir no campo de pesquisa. Uma presença meditativa, entendida como "a plena consciência de estar, aqui e agora, no menor gesto, na menor atividade da vida cotidiana" (BARBIER, 2002, p. 99) faz o pesquisador entrar em um estado de hiperobservação, permitindo a escuta-ação espontânea, uma ação imediata e adaptada perfeitamente ao acontecimento.

A principal técnica para registro dos dados coletados a partir da observação participante e da escuta sensível multirreferencial, é o diário de itinerância, um caderno de anotação de campo que abarca as especificidades de uma pesquisa-ação predominante existencial. Por isso, o uso do termo "itinerância" para fazer uma diferenciação com o conceito de uma simples trajetória, e se aproximar do conceito de um "[...] percurso estrutural de uma existência concreta tal qual se manifesta pouco a pouco, e de uma maneira inacabada, no emaranhado dos diversos itinerários percorridos por uma pessoa ou por um grupo" (BARBIER, 2002, p. 134).

No diário de itinerância buscamos registrar as vicissitudes do cotidiano, como as afetividades e as reações em relação aos fatos circundantes. Afetividades e reações essas 
não somente dos participantes da pesquisa como também do próprio pesquisador. Por estar apoiado em uma abordagem transversal, o conhecimento gerado a partir desse método de pesquisa não está no acompanhamento paralelo feito pelo pesquisador, que de forma neutra observa os acontecimentos, mas, sim, no encontro do pesquisador com o grupo e naquilo que os atravessam e os modificam mutuamente, gerando afetos e reações a partir desses encontros. Para Barbier (2002), o diário de itinerância

Trata-se de um instrumento de investigação sobre si mesmo em relação ao grupo e em que se emprega a tríplice escuta/palavra clínica, filosófica e poética - da abordagem transversal. Bloco de apontamentos no qual cada um anota o que sente, o que pensa, o que medita, o que poetiza, o que retém de uma teoria, de uma conversa, o que constrói para dar sentido à vida (p. 133).

O diário de itinerânicia assemelha-se ao diário íntimo por registrar pensamentos, sentimentos, desejos, sonhos muito secretos, ou seja, por ir fundo no imaginário do pesquisador profissional, em caráter íntimo com a afetividade. Mas, diferentemente de um diário íntimo, que nem sempre é feito para ser publicado, ele deve ser feito com cuidado e respeito às pessoas envolvidas. Assim como o diário íntimo, ele é feito diariamente e pode conter uma autobiografia, posto que a volta ao passado, lembranças da infância, que façam sentido com os acontecimentos atuais, são utilizados na pesquisa-ação existencial.

Outras fontes de coleta de dados utilizado na pesquisa foram os questionários. Apesar de nem sempre serem aplicados em pesquisa-ação, o uso de questionários se fez útil no sentido de compreender e aprofundar elementos macros e de relações com o grande volume de professores envolvidos. O questionário se constituiu como um recurso de apoio, não como essência das informações. É essencial que não se perca o caráter qualitativo da pesquisa, pois mesmo com o uso de processamento estatístico dos dados do questionário "O processamento adequado sempre requer uma função argumentativa dando relevo e conteúdo social às interpretações" (THIOLLENT, 1988, p. 65).

Ou seja, o levantamento quantitativo a partir das respostas de um questionário tem uma função auxiliar ao processo qualitativo de uma pesquisa-ação.

Segundo Barbier (2002), todos os tipos de pesquisa-ação possuem em comum o que chamou de abordagem em espiral, uma descrição estética da prática usual na pesquisa-ação de refletir, após a ação, sobre as mudanças ocorridas, elevando, a cada 
ação, a compreensão do objeto para um patamar de maior entendimento. Cada novo olhar sobre o mesmo objeto nunca vai ser igual ao olhar anterior.

Significa que todo avanço em pesquisa-ação implica o efeito recursivo em função de uma reflexão permanente sobre a ação. Inversamente, porém, todo segmento de ação engendra ipso facto um crescimento do espírito de pesquisa. Nada de pesquisa sem ação, nada de ação sem pesquisa, como dizia Lewin. A abordagem em espiral supõe igualmente que, mesmo se nós nunca nos banhamos duas vezes no mesmo rio, segundo a fórmula heraclitiana, ocorre-nos olhar duas vezes o mesmo objeto sob ângulos diferentes. É o espírito mesmo da multirreferencialidade. Como o sabem todos os sábios, ninguém jamais deixará de contemplar um sorriso de criança. Aliás, será o mesmo sorriso de um instante ao outro? Assim, na ação, o pesquisador passa e repassa seu olhar sobre o "objeto", isto é, sobre o que vai em direção ao fim de um processo realizando uma ação de mudança permanente. Seu objeto constantemente lhe escapa, arrastado pelo fluxo da vida. Ele o examina continuamente. Implicando-se sem querer retê-lo (p. 117).

Nesse movimento circular, a cada nova passagem sobre a problemática abordada, após uma reflexão prévia e uma ação planejada, uma elevação de consciência é acrescentada ao entendimento desse objeto. Por mais que o problema não tenha se resolvido por completo, podemos dizer que o conhecimento sobre ele mudou e, com isso, a forma de se relacionar com esse problema também irá mudar.

Esse conceito de Barbier (2002) eleva o entendimento do método da pesquisaação de um plano bidimensional para um plano tridimensional, levando em consideração não um círculo fechado, no qual se volta ao mesmo ponto enquanto o problema não estiver completamente sanado, mas uma espiral na qual, ao retornar ao objeto para uma reavaliação sempre se está em um nível superior de entendimento desse objeto, mesmo que ele não esteja sanado. Um simples olhar diferenciado sobre um problema pode gerar uma nova forma de se relacionar com esse problema, o que, por si só, já é uma evolução.

\section{A espiral da pesquisa-ação}

Por não ter um problema a priori, a pesquisa-ação carece de uma pesquisa de base, que possibilite aos pesquisadores ter informações gerais acerca do campo a ser estudado e aprofundado. Nesse sentido, partimos dos estudos de Branco (2008), por ter sido uma pesquisa-ação existencial realizada no mesmo local, com o mesmo grupo 
(professores), embora em período anterior, com cenário e desenho de investigação distintos.

$\mathrm{Na}$ pesquisa de Branco (2008), o cenário encontrado foi de um adoecimento generalizado das professoras de classe hospitalar. O motivo era o estresse ocasionado pelo vínculo estabelecido com alunos/pacientes em situação de sofrimento.

A intervenção da pesquisa utilizada por Branco (2008) foi a capacitação das professoras por meio da aplicação de uma técnica de grupo denominada de Grupo Balint. Essa técnica tinha uma função psicoterápica com foco na atuação profissional, o que ocorreu com sucesso, melhorando a qualidade de vida das professoras no trabalho.

Em campo, o cenário encontrado no NAEH era diferente daquele encontrado por Branco (2008), em que havia muitas professoras adoecidas e sem nenhum apoio psicoterápico. Apesar de não encontrarmos indícios de doenças ou transtornos que constem dentro do código internacional das doenças (CID 10), como uma síndrome de burnout, percebemos angústias e sofrimentos expressos nas ações, diálogos e pedido de ajuda à equipe coordenadora do NAEH e pesquisadores em campo.

Nos processos de interação com o coletivo de professores, sob apoio do psicólogo institucional e coordenação geral, com atendimentos individuais e coletivos, buscamos participar do cotidiano do trabalho dos professores e demais profissionais. A partir da proposta de transversalidade da escuta sensível, pudemos perceber algumas situações em que se encontravam os integrantes ou sujeitos da pesquisa.

Uma das queixas iniciais tomadas como desafio de enfrentamento era fazer atendimento educacional com educandos com transtornos mentais.

Da mesma forma que as professoras se sentiam inseguras com relação a uma atuação no campo da saúde mental, um integrante da equipe de pesquisa também se sentia bastante inseguro no estudo, por ser da área da saúde e se encontrar atuando no campo da educação. A classe hospitalar e atendimento educacional domiciliar, como visto, é uma área de muitos saberes, mas que suscita angústias por nos colocar em contato com saberes que, muitas vezes, não dominamos.

Ao compartilharmos com os professores nossas angústias, inseguranças, desconhecimentos, inexperiências com alguns fatores, percebemos maior aproximação e abertura por parte dos profissionais da educação.

A pesquisa-ação pressupõe um diálogo constante entre pesquisadores e sujeitos participantes, no sentido de estabelecer vínculos de confiança e engajamento de todos (BARBIER, 2002). 
Por se tratar de profissionais da área de educação lidando com situações do campo da saúde, dentre as muitas discussões, temas aprofundados e demandas apresentadas, suscitou-se o desejo de uma capacitação que pudesse proporcionar aprofundamento no conhecimento acerca do trabalho com educandos com transtorno mental. Os docentes queriam entender mais sobre o mundo da saúde mental e como poderiam tais conhecimentos para melhorar suas relações com esses alunos.

A noção do trabalho em conjunto, no caso um trabalho intersetorial, é fundamental quando fazemos saúde mental e quando uma parte falha isso pode comprometer a atuação dos outros setores envolvidos. Quando entendemos que faltou o apoio da equipe de saúde no tratamento dos casos de transtorno, estamos falando da necessidade de trabalhar a intersetorialidade nos tratamentos em saúde mental.

Assim, uma vez confirmadas as hipóteses junto ao público-alvo, em reunião com toda equipe, ficou decidido, em conjunto, que, para a primeira hipótese de esclarecimento levantada (falta de capacitação dos profissionais do NAEH para lidar com alunos com transtorno mental), a ação adequada seria a realização de um curso de capacitação em saúde mental voltado para a equipe do NAEH. Para a segunda hipótese de esclarecimento (falta de apoio da equipe de saúde mental, gerando angústia na equipe do NAEH), a ação adequada seria capacitar a equipe coordenadora do NAEH para trabalhar na rede de atenção psicossocial. Ficou acordado, também, nessa reunião, que a primeira ação a ser desenvolvida seria o curso de capacitação em saúde mental.

Embora o estudo tenha provocado uma diversidade de ações no campo do trabalhador de educação no campo da saúde, neste texto, nos propomos apresentar a experiência do curso de formação sobre saúde mental ofertado aos professores do $\mathrm{NAEH}$

\section{A formação como uma das resultantes da pesquisa-ação}

A formação foi elaborada de acordo com uma proposta adaptada do método Problem-Based Learning, mais conhecido como PBL, uma metodologia de aprendizagem baseada em problemas e que elege como foco o aprendizado centrado no aluno. O PBL é um modelo pedagógico recomendado por sociedades de escolas médicas do Brasil e diversos outros países, inspirado em longas experiências realizadas no Canadá (MacMaster) e na Holanda (Maastricht) (BERBEL, 1998). A construção da 
autonomia na aprendizagem, pressuposto do PBL, perpassa pela orientação, discussão e resolução de problemas formulados pelos educadores (PERRENOUD, 2002).

No PBL, as discussões ocorrem em grupos, cabendo ao professor o papel de mediador desse processo. A aprendizagem, nesse sentido, não está ligada direta e exclusivamente nas atividades de ensino, como ocorre nos moldes tradicionais. Compete aos alunos assumirem o papel ativo de buscar o conhecimento (CABRAL; ALMEIDA, 2014).

Os responsáveis pela construção do conhecimento do grupo são, portanto, os estudantes, no caso, as professoras do NAEH, que tiveram orientações, como indicações de leitura, mas que eram livres para pesquisar outras fontes de referência para basear a produção dos seus trabalhos. A autonomia na construção do conhecimento é uma das bases da filosofia do PBL.

O processo de problematização foi realizado por meio do estudo de casos, com diferentes níveis de complexidade, com temáticas próximas da realidade do trabalho das professoras. As professoras do NAEH discutiam o caso e elaboravam soluções por meio de estudos de aprofundamento. Antes de avançar para o próximo módulo apresentavam o resultado das discussões e soluções propostas. Lembrando que outro princípio do PBL é o trabalho coletivo e colaborativo, embora cada estudante se projete e empenhe em sua perspectiva e expectativa de aprendizagem.

Tomamos como referência para elaboração dos casos de estudo as narrativas literárias. Essa ferramenta, proposta de Barros (2007), se mostrou útil para ser usada na formação de professores de classe hospitalar e atendimento domiciliar. É uma adaptação das narrativas em medicina usadas para a capacitação dos profissionais da saúde. $\mathrm{O}$ uso dessa técnica, segundo propõe, facilita o estudo de situações complexas em que ocorre a influência de diversos setores profissionais. Como pretendíamos capacitar as professoras e a equipe coordenadora do NAEH para um trabalho intersetorial, as narrativas literárias nos pareceram uma alternativa adequada.

Por serem histórias criadas com base em experiências reais vividas pelas professoras, as narrativas literárias se aproximavam da matriz relativista/relacional para qualificação no trabalho, que, também, usamos como referência para o curso de capacitação. A matriz relativista/relacional entende a formação como algo complexo; reconhece a importância da teoria, mas se propõe ir além dela; entende a formação com algo que ocorre dentro de seu contexto histórico-cultural e durante a prática do saber que se pretende dominar (ALVES; SOARES JÚNIOR, 2015). 
A partir dos pontos críticos levantados durante a vivência de campo, escuta sensível, questionário aplicado e da experiência do psicólogo do NAEH, começamos a elaborar as primeiras ideias. Foram vários rascunhos até chegarmos ao ponto de, coletivamente, aprovarmos dois casos que foram utilizados no curso de formação6: o "Caso da professora Marilda", abordando o tema de transtorno mental e o "Caso da professora Mileide", abordando o tema adoecimento psíquico do professor.

Como material de apoio ao estudo do caso da professora Marilda foi indicada às docentes em curso a linha-guia em saúde mental da Secretaria de Estado de Saúde de Minas Gerais. Entre muitos materiais avaliados para apoio aos estudos, esse foi o escolhido por ser um material didático, construído para não especialistas, que lidam com saúde mental, entenderem a forma como se faz saúde mental atualmente. Esse material aborda diversos assuntos, que permeiam o tratamento do transtornado mental, falando sobre a história e a evolução do tratamento de transtornados, da antiguidade até os dias atuais, com a reforma psiquiátrica. Explica os principais transtornos e seus sintomas e como se organiza, na prática, a atual política de saúde mental.

Como material de apoio ao estudo do primeiro caso, disponibilizamos dois trechos da dissertação e três trechos da tese de Branco (2001, 2008), materiais escolhidos por conter definições dos conceitos psicológicos para trabalhar a relação médico/paciente, mas com possibilidade de adaptação na relação professor/aluno.

O curso, em formato semipresencial, foi estruturado em módulos. A cada módulo era apresentado um caso em um encontro presencial seguido de aprofundamentos teórico-metodológico e discussões acerca dos temas propostos. Em ambiente virtual, a distância, os grupos de trabalho, formados de forma democrática, aprofundavam sobre os casos utilizando-se de várias mídias interativas como blogs, chats, e-mails, redes sociais, dentre outros, em conformidade com o objetivo de aprendizagem de cada grupo.

Cada grupo, de posse do caso, levantava as palavras-chave, estudava os conceitos, levantava hipóteses de solução, definia os objetivos de aprendizagem e propunha as propostas de solução. Inicialmente, cada educando, individualmente, fazia a construção de tais elementos, compartilhando, no ambiente virtual, suas ideias com os colegas do grupo. Ao discutir sobre o caso, apresentava uma síntese, contendo os pontos

6 Todo material desenvolvido, discutido, trabalhado, bem como as filmagens dos encontros presenciais realizados na UFG encontram-se disponíveis no blog do NAEH, com acesso pelo endereço eletrônico: <http://naehgoias.blogspot.com.br/p/formacao-continuada.html>. 
de convergência (aproximações dos resultados) e os pontos de divergência (discordância do grupo). As sínteses eram apresentadas de forma expositiva, nos encontros presenciais seguintes, aos formadores e aos demais grupos.

O curso ocorreu com o apoio e suporte do Laboratório de Pesquisa, Desenvolvimento e Inovação em Mídias Interativas da UFG (Media Lab/UFG), convênio firmado entre a SEDUCE e a UFG. Com o título de "Curso de Formação de Professores para Classes Hospitalares (FPCH)", o curso, com carga de 120 horas-aula, forneceu certificação de curso de extensão, emitido pelo Media Lab/UFG. O curso foi realizado no período de 04 de maio a 30 de junho de 2015, com seis encontros presenciais $(04 / 05 ; 18 / 05 ; 01 / 06 ; 15 / 06 ; 29 / 06$ e 30/06).

Os encontros presenciais foram gravados e transmitidos ao vivo (online), para que os professores do interior do Estado de Goiás, que não pudessem comparecer ao curso, na Capital, tivessem a oportunidade de acompanhar as discussões, palestras e apresentações. Essa foi mais uma das oportunidades criadas pela formatação do curso em mídias interativas. Participaram do curso, professoras da rede que atuam em outras escolas, mas com extensão de carga-horária no NAEH; gestores do NAEH; professores formadores lotados no departamento pedagógico da SEDUCE; mediadores da inclusão da Gerência de Ensino Especial; profissionais dos hospitais onde são realizados os atendimentos pedagógicos; e alunos do curso de Biologia do PetBIO, totalizando 150 profissionais da educação.

O formato do curso proporcionou, além da interação entre os participantes, todo o material, desde os encontros presenciais, passando pelas palestras, estudos de casos, o material de apoio, até a produção dos grupos, ficou disponível para acesso no sítio do Media Lab da UFG, de forma que, mesmo após o término do curso, os interessados poderiam acessar os casos e os vídeos dos encontros presenciais, possibilitando uma formação continuada também para futuros professores do NAEH.

Além da elaboração dos casos, tivemos oportunidades de proferir uma palestra sobre a temática de transtorno mental, relatando, inclusive, nossa experiência de trabalho na área. Falamos sobre a história da loucura, a partir de Foucault (1987), sobre a reforma psiquiátrica no mundo e no Brasil e a nova política de saúde mental brasileira. Os principais transtornos, também, foram abordados como depressão, transtornos de humor, transtornos de ansiedade, esquizofrenia e transtorno obsessivo compulsivo (TOC). 
Após o término do curso fizemos uma avaliação coletiva da proposta, passo importante e previsto na pesquisa-ação existencial, momento quando fazemos a reflexão sobre as ações empreendidas.

Em termos avaliativos do coletivo, era perceptível que o cenário inicial já havia mudado bastante em relação à questão da saúde mental. Ao questionar sobre como encarava os atendimentos a alunos com transtorno mental após as ações desenvolvidas, um dos membros do pesquisador coletivo respondeu:

Mudou bastante coisa, porque antes nós tínhamos a questão da insegurança. Chegava um caso de aluno com transtorno mental e, muitas vezes, nós ficávamos em dúvida se era caso para ser atendido no NAEH ou não. Mas tinha um laudo médico e acabávamos atendendo, pois não tínhamos elementos suficientes $e$ argumentos para discutir com as famílias se aquele era ou não um caso de atendimento no NAEH. Hoje, após o período da pesquisa, eu vejo que foi bastante positivo, porque nós já conseguimos dizer quando o atendimento não é do NAEHe elencar porque não é. Isso foi bastante positivo para fortalecer o trabalho do NAEH, para instrumentalizar na questão de conhecimentos teóricos e práticos. Ontem mesmo, conversando com uma mãe de aluno com transtorno, eu consegui mostrar que o filho pode, sim, frequentar a escola. (Relato 1)

Outro relato de professor diz respeito ao preconceito que afetava os profissionais do NAEH na lida com os alunos com transtorno, um tema que a pesquisa se propôs a abordar.

Tínhamos muito receio sobre o comportamento do esquizofrênico, pois o que mais amedronta o leigo é que a gente sabe que o esquizofrênico pode matar. Mas não tínhamos claro que ele, estando medicado e acompanhado, pode ter uma vida normal. E o curso feito por vocês veio esclarecer esse ponto e derrubar o preconceito. (Relato 2 ).

Outro participante da pesquisa expos sua avaliação sobre as mudanças ocorridas:

O olhar diferenciado de pesquisador e clínico que você[s] trouxe[ram] contribuiu bastante. Mesmo que as professoras sejam pessoas esclarecidas em vários aspectos, às vezes, até sobre transtorno mental, esse conhecimento é superficial e, às vezes, até arraigado em algum tipo de preconceito ou medo. Então, quando tem um olhar diferenciado de um profissional da área, isso contribui muito. Tenho certeza que nós conseguimos ajudar, tanto você quanto eu, nós, a diminuir o medo e o preconceito com relação a algum tipo de transtorno. [...] Antes, havia uma ressalva das professoras com relação aos alunos com transtorno. Hoje, a dificuldade dos alunos fica em segundo plano, a gente vê a preocupação com o aluno, como ser humano, a preocupação com ele, como aluno, de que vai vencer a dificuldade que está passando e que vai voltar para a escola. (Relato 3).

Apesar de satisfeitos com a formação, alguns docentes ainda se sentiam angustiados no enfrentamento desses casos. Percebemos que os problemas eram os mesmos referentes à falta de apoio da equipe de saúde, que já havíamos constatado anteriormente. Assim sendo, era preciso nos debruçarmos, novamente, sobre o 
problema naquilo que Barbier (2002) chamou de realização em espiral, quando voltamos ao problema e o reavaliamos após cada ação. Notamos que o nível de esclarecimento sobre ele aumenta a cada ação; a cada ciclo da pesquisa-ação subimos um degrau na consciência a respeito da problemática envolvida no objeto abordado.

Embora não abordado neste texto, foram necessárias outras proposições de trabalho coletivo no sentido de avençarmos na espiral da pesquisa-ação proposta. A realização ações refletidas em espiral (ação-reflexão-ação), na nossa pesquisa, ocorre no momento em que a primeira ação aumenta o nível de consciência do pesquisador coletivo sobre o problema, permitindo que um novo planejamento ocorra para realização de uma nova abordagem, agora mais madura e mais próxima do objetivo de co-construção do objeto.

\section{Considerações finais}

As professoras das classes hospitalares e do atendimento educacional domiciliar encontram-se mais expostas aos riscos da saúde, por atuarem na interseção das áreas da saúde e da educação.

O sofrimento envolvido no atendimento a alunos com transtorno mental se revelou o tema mais emergente, entre os que afetavam a saúde das professoras do NAEH, como constatado no discurso das professoras, na escuta sensível, nos encontros psicoeducacionais, e nos resultados do questionário. Identificar os casos de atendimento educacional envolvendo transtorno mental como fator que afeta a saúde das professoras foi um objetivo específico da pesquisa importante para se planejar a formação da equipe coordenadora e das professoras.

No coletivo, a partir da participação efetiva, colaborativa e engajada de autores a atores na pesquisa, uma importante etapa do estudo foi direcionada para a abordagem das dificuldades no atendimento de casos envolvendo transtorno mental.

A proposta de um curso de formação de professores atuantes com alunos em processo de adoecimento foi, do ponto de vista pedagógico, bastante inovador e, em nossa avaliação, trouxe resultados satisfatórios, segundo seus propósitos.

Houve uma ressignificação da representação de "loucura" nos atores da pesquisa, que passou, então, a ter um novo sentido no imaginário dos professores e da equipe coordenadora do NAEH, um sentido mais positivo e menos paralisante. Na avaliação final, identificamos, por meio dos relatos ocorridos, uma superação da 
insegurança em lidar com os casos envolvendo transtorno mental, devido ao aporte de informação teórica e prática esclarecedora sobre o tema, o que permitiu a atribuição de novos sentidos à sua prática.

É certo que um curso de formação apresenta seus limites, devido a característica conceitual, embora se tenha tentado aproximar de situações reais. Embora não contemplado neste texto, houve necessidade de aprofundamento em outras demandas de formação, no campo prático.

Os resultados positivos alcançados com relação à saúde das professoras demonstram a importância do cuidado que os gestores devem dispensar aos trabalhadores na gestão dos recursos humanos para dar vida à Política Nacional de Saúde do Trabalhador e da Trabalhadora (BRASIL, 2012). A efetivação dessa política, em âmbito nacional, poderia causar elevação significativa dos índices referentes à saúde da população brasileira.

Tendo em vista que a realidade de cada serviço e os fatores que incidem sobre a saúde dos trabalhadores são inúmeros e diferenciados em cada situação concreta, a ação proposta pesquisa não é replicável diretamente em outras realidades e, portanto, os resultados não podem, sem as devidas ressalvas, cuidados, adaptações, serem generalizados. Apesar disso, a pesquisa-ação demonstrou ser uma ferramenta útil aos gestores na promoção da saúde dos seus trabalhadores e na qualidade dos serviços prestados à população.

Em síntese, a participação do coletivo nas questões levantadas, o engajamento dos envolvidos para compreensão dos aspectos teóricos, a co-participação nas discussões e reflexões sobre as práticas de ensino sugeridas, bem como o olhar mais cuidadoso e menos estereotipado sobre a doença e seu reflexo social, trouxe avanço considerável no/para o grupo em estudo. o propósito da pesquisa-ação existencial de se tornar uma pesquisa com a participação ativa dos atores interessados diretamente em seu resultado, tanto na avaliação dos atores quanto dos autores foi satisfatoriamente alcançado.

\section{REFERÊNCIAS}

ALVES, W. F.; SOARES JÚNIOR, N. E. A noção de qualificação do trabalho nas pesquisas em educação: uma análise da produção acadêmica do GT Trabalho e Educação / ANPEd. Trabalho \& Educação, Belo Horizonte, v. 24, n. 1, p. 67-83, janabr, 2015. 
BARBIER, R. A pesquisa-ação. Brasília: Liber Livro Editora, 2002.

BARROS, A. S. S. Contribuições da educação profissional em saúde à formação para o trabalho em classes hospitalares. Cad. CEDES, Campinas, v. 27, n. 73, p. 257-278, dez. 2007.

BERBEL, N. A. N. A problematização e a aprendizagem baseada em problemas: diferentes termos ou diferentes caminhos? Interface: Comunicação, Saúde, Educação, v.2, n.2, 1998.

BRANCO, R. F. G. R. Capacitação de professores de Classe Hospitalar em relação professor-aluno/paciente na perspectiva balintiana. 2008. $180 \mathrm{f}$. Tese (Programa de Pós-Graduação em Educação) - Faculdade de Educação, Universidade Federal de Goiás, Goiânia.

BRANCO, R. F. G. R. O ensino na perspectiva dos Grupos Balint: um espaço de reflexão sobre o encontro do estudante de Medicina com o seu paciente. 2001. $155 \mathrm{f}$. Dissertação (Mestrado em Educação) - Faculdade de Educação, Universidade Federal de Goiás, Goiânia.

BRASIL. Diretrizes Nacionais para a Educação Especial na Educação Básica. Resolução CNE/CBE n ${ }^{\circ} 02$ de 11 de setembro de 2001. Diário Oficial da União, $n$. 177, Seção 1E de 14/09/01, pp.39-40. Brasília: Imprensa Oficial.

BRASIL. Ministério da Educação. Classe hospitalar e atendimento pedagógico domiciliar: estratégias e orientações. Secretaria de Educação Especial. Brasília: MEC/SEESP, 2002.

BRASIL. Ministério da Saúde. Portaria no 1.823, de 23 de agosto de 2012. Institui a Política Nacional de Saúde do Trabalhador e da Trabalhadora. Brasília.

CABRAL, H. S. R.; ALMEIDA, K. V. G. Problem Based Learning: aprendizagem baseada em problemas. Revista Interfaces: Saúde, Humanas e Tecnologia, ano 2, v. 2 , Número Especial, Faculdade Leão Sampaio, jun. 2012.

FOUCAULT, M. História da loucura. São Paulo. Ed. Perspectiva, 1987.

PERRENOUD, P. A prática reflexiva no ofício de professor: profissionalização e razão pedagógica. Porto Alegre: Atmed, 2002.

THIOLLENT, M. Metodologia da pesquisa-ação. São Paulo. Ed. Cortez. 1998. 


\section{Como citar este artigo:}

TEIXEIRA, Ricardo Antônio et al. Gonçalves Formação de professores de classe hospitalar em saúde mental como resultante de uma pesquisa-ação existencial. Temas em Educ. e Saúde, Araraquara, v.13, n.2, p. 317-334, jul./dez. 2017. Disponível em: <https://doi.org/10.26673/rtes.v13.n2.jul-dez.2017.10680>. E-ISSN: 2526-3471.

Submetido em: 20/05/2017

Aprovado em: 20/09/2017 